\title{
Tamoxifen Therapy for Breast Cancer and Endometrial Pathology
}

\author{
Lt Col SPS Kochar", Surg VAdm (Mrs) P Arora, sm, vsm ${ }^{+}$, Maj Gen AB Chattopadhyay (Retd)
}

\begin{abstract}
Background: Tamoxifen, used as adjuvant therapy for carcinoma breast in postmenopausal women to prevent relapse has estrogenic effect on the endometrium.

Methods: 104 patients on tamoxifen for more than six months were subjected to a clinical examination and transvaginal sonography. Patients with endometrial thickness $>8 \mathrm{~mm}$ were further evaluated by hysteroscopy and endometrial biopsy.

Results: $35(34 \%)$ patients were symptomatic. The average endometrial thickness was $11.2 \mathrm{~mm}$ which correlated with duration of tamoxifen use. $27(48 \%)$ patients had abnormal hysteroscopic findings. $35(63 \%)$ of endometrial biopsies revealed abnormal endometrium. One case of endometrial carcinoma was diagnosed. The results were statistically analysed. There is a significant association between symptomatic status and endometrial thickness and duration of tamoxifen use.

Conclusion: All patients on long term tamoxifen should be annually screened for endometrial pathology.
\end{abstract}

MJAFI 2005; 61 : 313-315

Key Words: Tamoxifen; Endometrium; Transvaginal sonography

\section{Introduction}

$\mathrm{T}$ amoxifen has been successfully used for more than a decade as adjuvant therapy for breast cancer in postmenopausal women with positive estrogen receptor proteins after conventional primary treatment. An increasing number of reports implicated induction of endometrial change with continued use of tamoxifen. Since tamoxifen confers an increased risk of endometrial cancer, gynaecologic surveillance of asymptomatic women is needed [1]. The present study was conducted to evaluate the effects of tamoxifen on endometrium, when given as an adjuvant therapy for breast cancer. The evaluation was done by transvaginal ultrasonography, hysteroscopy and endometrial biopsy.

\section{Material and Methods}

Patients of carcinoma breast on adjuvant tamoxifen therapy at an oncology center of a referral service hospital were included in this prospective study covering the period Oct 1999 to Oct 2001. Patients on tamoxifen for more than six months were subjected to clinical examination and transvaginal ultrasonography (TVS) for endometrial thickness. Endometrial thickness was measured in anteroposterior dimension and was considered normal when less than $8 \mathrm{~mm}$. Patients with endometrial thickness of more than $8 \mathrm{~mm}$ were further evaluated by conventional hysteroscopy and endometrial biopsy. Endometrial thickness was then correlated with hysteroscopic findings, histopathologic findings and duration of tamoxifen treatment.

\section{Results}

104 patients of carcinoma breast on tamoxifen treatment were included in the study. $35(34 \%)$ patients were on tamoxifen for a duration of $1-2$ years whereas only $14(13 \%)$ were on tamoxifen for more than 3 years. 35 patients $(34 \%)$ were symptomatic, whereas $69(66 \%)$ were asymptomatic (Table 1). 48 patients (46\%) showed endometrial thickness of less than $8 \mathrm{~mm}$ while $56(54 \%)$ showed endometrial thickness of $8 \mathrm{~mm}$ or more. The average endometrial thickness was 11.2 $\mathrm{mm}$ which correlated with the duration of tamoxifen use (Table 2). 56 patients with endometrial thickness $>8 \mathrm{~mm}$ were subjected to diagnostic hysteroscopy. $29(52 \%)$ had normal hysteroscopic findings, whereas 27 (48\%) had abnormal findings like hyperplasia, endometrial polyp or growth. As endometrial thickness increased, the incidence of abnormal finding increased (Table 3). 21 (37\%) of the endometrial biopsies revealed normal endometrium whereas $35(63 \%)$ had endometrial pathology. The commonest pathology was endometrial polyp in 12 patients. Endometrial hyperplasia with nuclear atypia in 5 patient had endometrial carcinoma in 1. The endometrial carcinoma occurred in a woman who was treated with tamoxifen for a duration of six years (Table 4). This patient was symptomatic.

\section{Discussion}

Ozsner et al have shown that tamoxifen use increases

\footnotetext{
*Reader (Obstetric and Gynaecology), Armed Forces Medical College, Pune, ${ }^{+}$Director General Medical Services (Navy), Naval Headquarters, New Delhi. "Ex-Commandant, CH (NC), c/o 56 APO.
}

Received : 10.10.2002; Accepted : 26.04.2005 
Table 1

Duration of Tamoxifen use and symptom status (n-104)

$\begin{array}{llcc}\text { Duration of use (Tamoxifen) } & & \\ & \text { No of patients } & \text { Symptomatic } & \text { Asymptomatic } \\ 6 \text { months - 1 year } & 23(22 \%) & 4 & 19 \\ \text { 1 year - 2 years } & 35(34 \%) & 8 & 27 \\ 2 \text { years - 3 years } & 32(31 \%) & 15 & 17 \\ >3 \text { years } & 14(13 \%) & 8 & 6 \\ \text { Total } & 104 & 35(34 \%) & 69(66 \%)\end{array}$

[P value by chi - square test $<0.01$. There is a significant linear trend between the symptomatic status and duration of tamoxifen use]

Table 2

Duration of tamoxifen use and endometrial thickness (n-104)

$\begin{array}{lcc}\text { Duration of use } & <8 \mathrm{~mm} \text { thickness } & >8 \mathrm{~mm} \text { thickness } \\ 6 \text { months }-1 \text { year } & 16 & 6 \\ 1 \text { year }-2 \text { years } & 14 & 20 \\ 2 \text { years }-3 \text { years } & 10 & 21 \\ >3 \text { years } & 5 & 9\end{array}$

[P value by chi - square test $<0.01$. There is a significant linear trend between number of patients with $>8 \mathrm{~mm}$ endometrial thickness and duration of tamoxifen use]

the risk of endometrial cancer and premalignant change [2]. They also noticed significant relation between endometrial thickness and duration of tamoxifen treatment (P-0.025) as in the present study. Hann et al found abnormal endometrial biopsy in $44 \%$ women treated with tamoxifen for less than 5 years whereas $58 \%$ of endometrial biopsies revealed abnormal results when duration of tamoxifen treatment was $>5$ years [3].

Katase et al concluded that tamoxifen does not appear to increase subsequent endometrial carcinoma in patients with primary breast carcinoma who underwent annual screening for gynaecologic cancer [4]. In contrast, the present study has shown one case of endometrial carcinoma and 5 patients of endometrial hyperplasia with nuclear atypia. This shows significant risk ( $p-0.026)$ of premalignant and malignant change in patients on long term tamoxifen.

Peters-Engl et al demonstrated that clinical benefits of tamoxifen greatly outweigh the risk [5]. They recommended annual follow up of patients on tamoxifen. Cohen et al showed that $28.6 \%$ of patients on tamoxifen had endometrial pathology [6]. The incidence was significantly more in symptomatic patients. Seoud et al concluded that the value of routine screening for endometrial pathology in patients on tamoxifen is controversial. They found that all patients who developed an abnormal endometrium had abnormal vaginal bleeding [7]. Bernstein et al in a case control study concluded
Table 3

Endometrial thickness and hysteroscopy findings (n-56 )

$\begin{array}{lcc}\text { Endometrial thickness } & \text { Normal study } & \text { Abnormal study } \\ 8-9.9 \mathrm{~mm} & 13 & 5 \\ 10-11.9 \mathrm{~mm} & 6 & 6 \\ 12-13.9 \mathrm{~mm} & 5 & 7 \\ 14-15.9 \mathrm{~mm} & 2 & 3 \\ 16-17.9 \mathrm{~mm} & 2 & 3 \\ \geq 18 \mathrm{~mm} & 1 & 3\end{array}$

Table 4

Histopathological findings (n-56)

$\begin{array}{lcr}\text { Histopathological finding } & \text { No of patients } & \text { Percentage } \\ \text { Normal endometrium } & 21 & 37 \% \\ \text { Endometrial polyps } & 12 & 22 \% \\ \text { Endocervical polyps } & 4 & 7 \% \\ \text { Cystic hyperplasia } & 3 & 5 \% \\ \text { Adenomatous hyperplasia } & 8 & 14 \% \\ \text { Endometrial hyperplasia } & & \\ \quad \text { with nuclear atypia } & 5 & 9 \% \\ \text { Endometrial cancer } & 1 & 2 \% \\ \text { Insufficient sample } & 2 & 4 \%\end{array}$

that endometrial cancer associated with tamoxifen use and the risk increased with the duration of tamoxifen use [8]. Prior use of estrogen replacement therapy (ERT) increased risk associated with tamoxifen use.

In a meta analysis, Macmohan concluded that an association exists between endometrial cancer and tamoxifen use [9].

\section{Conclusion}

The present study has shown that long term use of tamoxifen as adjuvant therapy for carcinoma breast is associated with endometrial pathology. Endometrial thickness is increased in such patients and is related to the duration of tamoxifen use $(p<.01)$. There is a significant risk of premalignant and malignant lesions of endometrium in patients on long term tamoxifen. All patients on long term tamoxifen should be annually screened for endometrial pathology.

\section{Acknowledgement}

The authors thank (Mrs) Seema R Patrikar of AFMC for the statistical analysis.

\section{References}

1. Burgmann EJ and Goodman A. Surveillance for Endometrial Cancer in women receiving tamoxifen. Annals of Internal Medicine 1999;131:127-35.

2. Ozsener S, Itil I, Dikmen Y. Endometrial pathology of 104 postmenopausal breast cancer patients treated with tamoxifen. Eur J Gynaecol Oncol 1998; 19(6): 580-3.

3. Hann LE, Bach AM, Tao Y, Baum HJ, Barakat RR. Endometrial thickness in tamoxifen-treated patients: correlation with clinical 
and pathological findings. Am J Roentgenol 1997; 168 (3): 657-61.

4. Katase K, Sugiyama Y, Hasumi K, Yoshimoto M, Kasumi F. The incidence of subsequent endometrial carcinoma with tamoxifen use in patients with primary breast carcinoma. Cancer 1998; 82 (9): 1698-703.

5. Peters-Engl C, Frank W, Danmayr E, Friedl HP, Leodolter S, Medl M. Association between endometrial cancer and tamoxifen treatment of breast cancer. Breast Cancer Res Treat 1999; 54 (3): 255-60.

6. Cohen I, Perel E, Flex D, et al. Endometrial pathology in postmenopausal tamoxifen treatment: comparision between gynaecologically symptomatic and asymptomatic breast cancer patients. J Clin Pathol 1999; 52 (4): 278-82.

7. Seoud M, Shamseddine A, Khalil A, et al. Tamoxifen and endometrial pathologies: a prospective study. Gynaecol Oncol 1999; 75 (1): 15-9.

8. Bernstein L, Deapen D, Schwartz SM, et al. Tamoxifen therapy for breast cancer and endometrial cancer risk. J Natl Cancer Inst 1999; 91 (19): 1654-62.

9. MacMahon B. Overview of studies on endometrial cancer and other types of cancer in humans: perspectives of an epidemiologist. Semin Oncol 1997; 24(1): 122-39.

\section{JOURNAL INFORMATION}

The journal is indexed/abstracted by ExtraMED, Index Medicus of Southeast Asia, International Abstracts of Biological Sciences, Abstracts of World Medicine, IndMED, Hygiene and Tropical Disease Abstracts and EMBASE.

The IndMED database is accessible on internet at the website http://indmed.nic.in

Bibliographic details of the Journal available on Website http://indmed.nic.in

At present you will find full text articles for the year 2003-2004 at http://medind.nic.in the site. Old issues will gradually be uploaded.

From IndMED site you can access, MJAFI Journal directly by typing in the search box jid-maa. If specific articles published in MJAFI are to be searched e.g. articles pertaining to malaria, type in the search box "malaria and jid-maa".

Articles can also be accessed directly at website www.google.com by feeding in keywords/author's name/title of the article.

Guidelines for authors appear in January issue every year.

Authors' Index, Subject Index and Contents of the Volume appear in October issue every year 